\title{
Optimization Design and Simulation Analysis of the Securing Position Based on New Type Flat Car
}

\author{
Run-Hua Qian ${ }^{1, \text { a) }), Y i ~ W u ~}{ }^{1, b}$ )
}

${ }^{1}$ Department of Mechanical Engineering, Academy of Armored Force Engineering, Beijing 100072, China

a) qian_aafe@126.com, ${ }^{\text {b) }}$ wuyi_zzu @163.com

Keywords: Optimization design of securing point; Heavy and large cargos; MATLAB

\begin{abstract}
In view of the present problems that the wooden block reinforcement effect is poor and can't solve the sliding problems caused by inertia of coupling impact. Now we plane to design a kind of new type flat car with chain-Strengthening-equipment to solve the loading and reinforcement problems of heavy and large cargos. Through the establishment of mechanical model and mathematical model, and programming simulation of MATLAB to provides a calculation method of the optimal lashing point of loading and reinforcement. Taking a kind of tracked vehicle as an example to calculating its optimal securing position. Results showed that there has larger gap between the cargos optimal securing position and the existing flat cars fixed point.
\end{abstract}

\section{INTRUDICTION}

The loading and reinforcement of big and heavy cargos have a great significance on the safety of rail freight transport. Big heavy goods have a large inertia force, so wooden block can't meet the requirements of high speed coupling impact. In the process of rail transportation, big heavy goods have occurred slippage phenomenon many times which leads to buckle car arrangement. It seriously affected the flat car running speed stability and security.

Aim at the big heavy goods' loading and reinforcement in the process of railway transport, different countries have different strengthening methods and strengthening equipment. In our country, reinforcing tracked vehicles only with wooden block, supplemented by pull reinforcement for them if necessary. But the reinforcement method can't guarantee the safety of railway freight. US armed forces in order to ensure the safety of wheeled and tracked equipment in the railway transport, they research and developed the chain-Strengthening-equipment. And it has been comprehensively applied to the loading and reinforcement work of national defense wheeled and crawler equipment.

As shown in figure 1, chain-Strengthening-equipment is made up of reinforce chain, sliding rail, sliding block. Reinforce chain connects vehicles and slide block, the sliding rail is in the flat car floor, and the sliding block can move in the sliding rail. So you can get more suitable securing points. This reinforcement method is not only convenient and quick, easy to master, and improved the security of the loading of reinforcement. Aim at the problem of loading reinforcement of the equipment, the reinforcement method in the equipment of our army in the railway transportation has a good application prospect.[1-2] But how will this reinforcement method is applied to our rail flat car and how to install the equipment which remains to be further analyzed. 


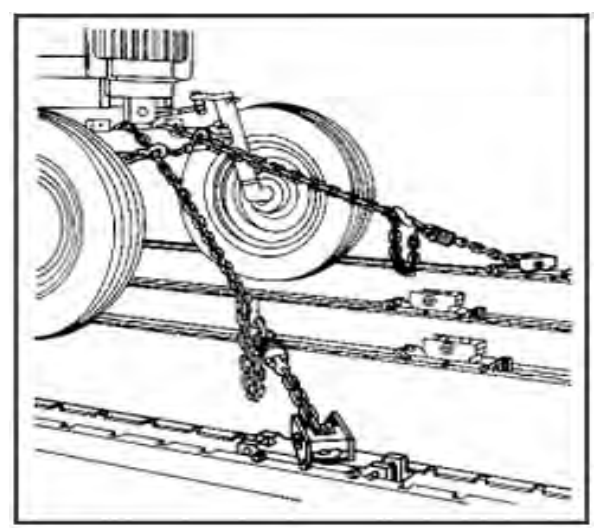

FIGURE 1, Chain-Strengthening-Equipment

The chain-Strengthening-equipment's settings on the flat car has great relationship with the cargos' optimal securing points. So you should firstly find the calculation method of solving the optimal securing point of goods.

This article is in the view of the condition that the equipment vehicles often move even capsize, take a certain type of tracked vehicles as the basic sample loading goods, take the new type NX70 flat car as transport platform, figure out the reinforcement force by solving the reinforcement model, and work out the optimal angle and position by optimization and simulation. Putting forward a kind of method that solve the equipment optimal reinforcement points on the railroad flat car, which has an important significance for ensuring the new type chain-Strengthening-equipment's design parameters, increasing the speed of loading and reinforcement ,and ensuring equipment's safety stability in the railway transportation.

\section{MODEL ESTABLISHMENT}

\section{Mechanical Model}

The cargos on the flat car will be subject to a variety of external force when the train runs. In addition to the friction, gravity, pulling force is stable pressure, and the rest are unstable force. Because the stress of the whole equipment on the flat car is very complex and we don't need to take the internal force into account, so the whole equipment can be regarded as a rigid body. The simple force diagram as shown in figure 2:

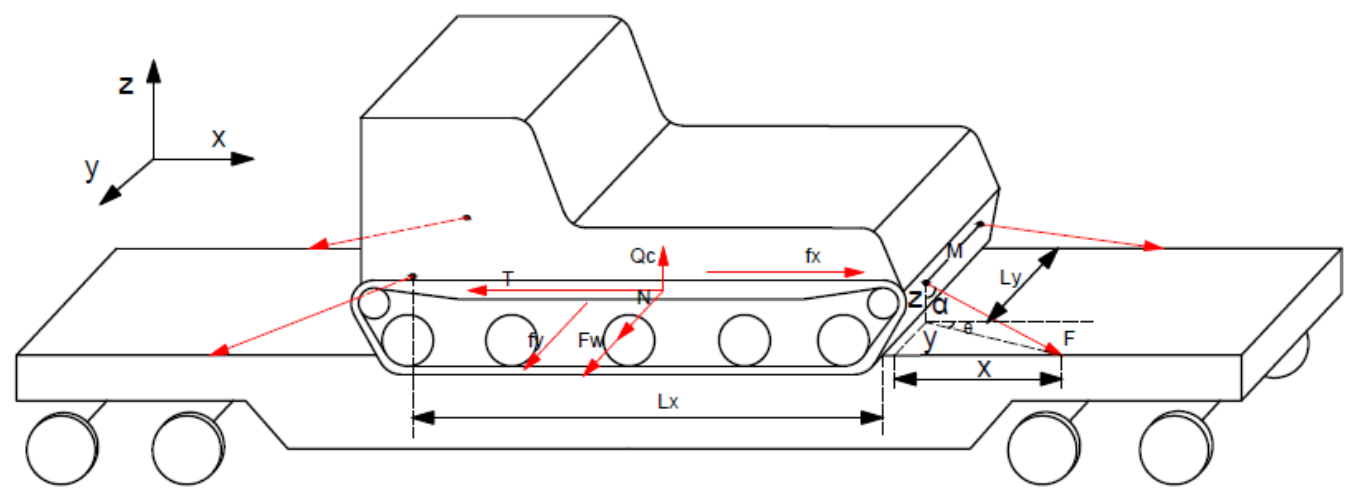

FIGURE 2, Simple force diagram

In the figure 2: $F$ is each pulling chain needs force; $L_{x}$ is the distance in $x$ axis between reinforcement point on equipment and longitudinal- capsize point; $\mathrm{L}_{\mathrm{y}}$ is the distance in $\mathrm{y}$ axis between reinforcement point on equipment and lateral-capsize point; $f_{x}$ is the longitudinal friction; $\mathrm{f}_{\mathrm{y}}$ is the lateral friction; $T$ is the longitudinal inertia force; $N$ is the lateral inertia force; $\mathrm{Q}_{\mathrm{c}}$ is the vertical inertia force; $z$ is the distance that pulling chain's shadow in $Z$ axis; $y$ is the distance that pulling chain's shadow in Y axis; $x$ is the distance that pulling chain's shadow in X axis; $\alpha$ is the angle between pulling chain and $\mathrm{Z}$ axis; $\theta$ is the angle between pulling chain and $\mathrm{X}$ axis. 


\section{The Mathematical Constraint Model}

The instability of the goods mainly has three aspects including overturning, level moving and rolling. Tracked vehicles have a slim chance in rolling so we only consider the overturning and level moving. The stability of goods' test is evaluated by stability coefficient. The threshold value of stability coefficient often is 1.25(longitudinal level moving is 1).[3-4]

The reinforcement force need to meet the requirements that the goods are steady in level moving and won't capsize in longitudinal and lateral direction. Its Force distributing diagrammatic sketch is shown as figure 3 and figure 4 . The above can be summed up in "stability constraints" shown as formula (1)-(6); The calculation of reinforcement force need to meet the right spatial geometric relationships what are summed up in "Geometric constraints " shown as formula (7)-(13); Because what we deal is actual engineering problems, so variables $\mathrm{x}$ and $\mathrm{y}$ should be restricted by the actual parameters of flat car and loading equipment. The above can be summed up in "The actual constraints" shown as formula (14), (15).

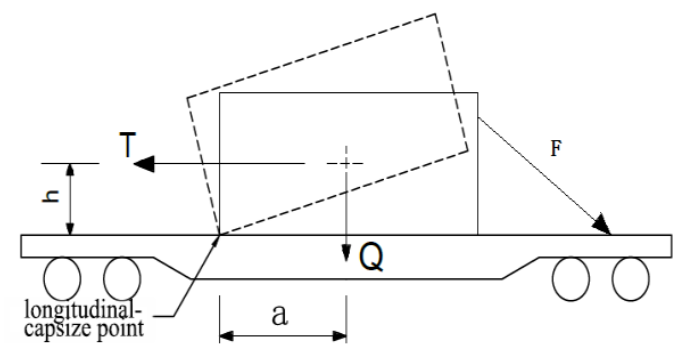

FIGURE 3, Longitudinal overthrow schematic diagram

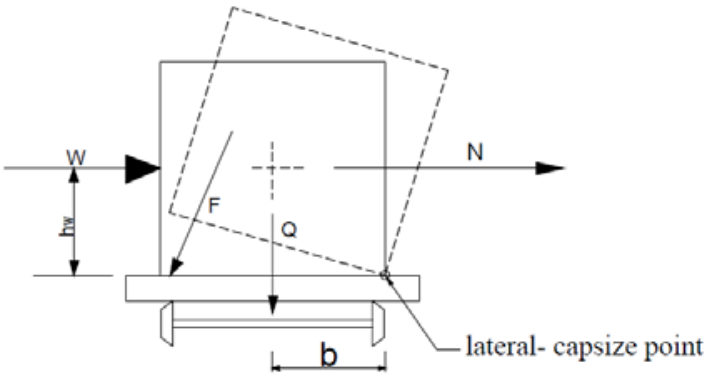

FIGURE 4, Lateral overthrow schematic diagram

We need to minimize the force in the pull chain under the above three constrains. The mathematical optimization model is established as follows:

$$
\min f(x, y)=F
$$

$$
\begin{array}{ll}
\text { s.t. } & 9.8 Q a+2 F_{x} Z+2 F_{z} L_{x}+1.25 T h \geq 0 \\
& 9.8 Q b+2 F_{y} Z+2 F_{z} L_{y}-1.25\left(N h+W h_{w}\right) \geq 0 \\
& f_{x}+2 F_{x}-T \geq 0 \\
& f_{y}+2 F_{y}-1.25(N+W) \geq 0 \\
f_{x}=\left(9.8 Q+2 F_{z}\right) \mu \\
f_{y}=\left(9.8 Q-Q_{c}+2 F_{z}\right) \mu \\
F_{x}=F \sin \alpha \cos \theta \\
F_{y}=F \sin \alpha \sin \theta \\
F_{z}=F \cos \alpha \\
\sin \alpha=\frac{\sqrt{x^{2}+y^{2}}}{\sqrt{x^{2}+y^{2}+z^{2}}} \\
\sin \theta=\frac{y}{\sqrt{x^{2}+y^{2}}} \\
\cos \alpha=\frac{\mathrm{z}}{\sqrt{x^{2}+y^{2}+z^{2}}} \\
\cos \theta=\frac{x}{\sqrt{x^{2}+y^{2}}} \\
0 \leq x \leq \mathrm{c} \\
0 \leq y \leq \mathrm{d}
\end{array}
$$

$\mathrm{f}(\mathrm{x}, \mathrm{y})$ represent the formula of pull reinforcement force about $x, y$; Q represent equipment mass; a represent the distance in level direction between center of gravity and longitudinal- capsize point; $h$ represent the distance between center of gravity and flat car floor; $h_{w}$ represent the height of crosswind point; $\mu$ represent the friction coefficient; $\mathrm{c}$, $\mathrm{d}$ represent the upper bound of $x, y$ 
respectively; b represent the Horizontal projection distance between center of gravity and lateral-capsize point.

Observe the constraint condition, easy to judge that constrains are continuous function, and $x, y$ values range is bounded. The continuous function must have the most value in the bounded closed interval. So there must be an optimal solution to the constrained optimization model. [5-8] However, due to the inability to determine the specific expression of $f(x, y)$, So it is difficult to solve the problem with mathematical method. We will through MATLAB programming with exhaustive method to solve the optimal value. $F_{x}, F_{y}, F_{z}$ respectively represent the projection of $F$ in $\mathrm{x}, \mathrm{y}, \mathrm{z}$ axis.

\section{PROGRAMMING AND SIMULATION}

According to the mechanical calculation model, it is found that the tensile force of the pull chain is related to the inertial force of the cargo and the three variables of $\mathrm{x}, \mathrm{y}$ and $\mathrm{z}$. And if the cargos and flat car are certain, the inertial forces are certain too. While the $\mathrm{Z}$ value is determined by the location of the reinforcement points on the loading equipment, so under the condition that the loading equipment and carrying car are certain the pulling reinforcement force is only related with $\mathrm{x}$ and $\mathrm{y}$. So we just need to change the $x, y$ to calculate the appropriate securing position.

Because the flat car securing points can only be in the flat car floor, so the theoretical $x$ value range is $\left(0, \frac{\mathrm{L}_{\text {car }}-\mathrm{L}_{\text {goods }}}{2}\right) . L_{\text {car }}$ represent the length of flat car; $L_{\text {goods }}$ represent the contact length of goods and the floor of the flat car. The y value range is $\left(0, \frac{2.96-\mathrm{M}}{2}\right) .2 .96$ is the value that flat car width subtracting two mould weight width. $\mathrm{M}$ is the distance between two reinforcement points on equipment (it is assumed that the tracked vehicle centroid and the flat car center points are coincident). The steps of $\mathrm{x}$ and $\mathrm{y}$ are 0.01 , and $\mathrm{c}=\frac{\mathrm{L}_{\mathrm{car}}-\mathrm{L}_{\text {goods }}}{2}, \mathrm{~d}=\frac{2.96-\mathrm{M}}{2}$.

Programming solves the optimal value by exhaustive method. Through a nested loop, calculate each point's pulling force which is minimum and meet the constraints. And put it $r$ into the matrix FM in a certain order, and finally find the smallest value in the matrix FM, as well as its corresponding $\mathrm{x}, \mathrm{y}$ value. This procedure can get the optimal solution, and in order to further analyze the changes of the optimal value along with independent variable we can add some drawing commands at the end of the program.

The program block diagram is shown in figure 5: 


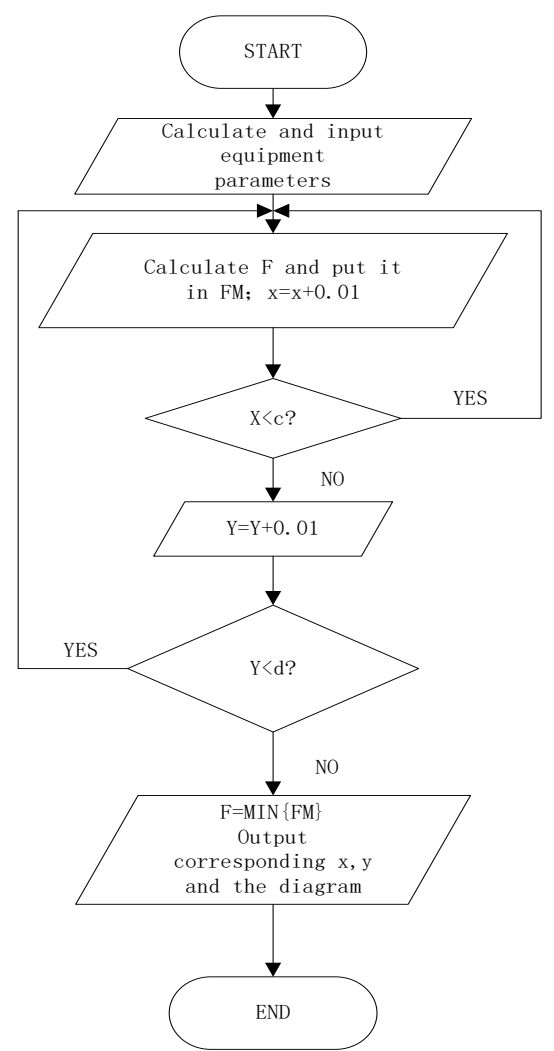

FIGURE 5, Program flow chart

\section{RESULTS OF SIMULATION AND ANALYSIS}

\section{Calculate Simulation Parameters}

When calculating pulling force we find that equipment inertial force and friction have the most obvious influence on calculation results. The method of calculating inertial force can reference the Rail Freight Organization. Take the new-type flat car NX70 loading a kind of tracked vehicle as an example, and choose the flexible reinforcing method. The results of parameters measured and calculated are shown in table 1:

TABLE 1, Simulation parameters

\begin{tabular}{|c|c|c|c|}
\hline Parameters & Symble & Value & Unit \\
\hline Crosswind & $W$ & 5.65 & $\mathrm{KN}$ \\
\hline Longitudinal offset of center of gravity & $P x$ & -0.105 & $m$ \\
\hline Lateral offset of center of gravity & Py & 0.6575 & $m$ \\
\hline Mass & $Q$ & 36.5 & $t$ \\
\hline Height of crosswind point & $h_{w}$ & 1.2 & $m$ \\
\hline Contact length between Track and floor & $L C$ & 3.932 & $m$ \\
\hline Height of center of gravity & $h$ & 1.195 & $m$ \\
\hline Height of securing point & $Z$ & 1.04 (front)、 0.67 (rear) & $m$ \\
\hline Width of securing point & $M$ & 1.15 (front)、 0.96 (rear) & $m$ \\
\hline $\begin{array}{l}\text { Distance between securing point and } \\
\text { longitudinal- capsize point }\end{array}$ & $L_{x}$ & 5.087 & $m$ \\
\hline $\begin{array}{l}\text { Distance between reinforcement point } \\
\text { and lateral- capsize point }\end{array}$ & $L_{y}$ & 2.058 & $m$ \\
\hline
\end{tabular}




\section{Result Analysis}

Because the vehicle's $\mathrm{z}$ and $\mathrm{M}$ in front are not same as the rear, and the value a is different from $\mathrm{x}$ negative direction when it is overthrown in $\mathrm{x}$ positive direction. So it should be divided into two cases, respectively, to find the optimal location of the securing point.

The optimization simulation of the front securing point is taken as an example. Through $\mathrm{y}=0$, $y=0.3, y=0.6, y=0.9$ four groups of data to research on pulling force variations with $\mathrm{x}$. The graph is shown in Figure 6. Figure 6 illustrates that when the $y$ is constant, firstly the pulling force decrease rapidly with $\mathrm{x}$ increase and then reach the minimum near 1.5, finally it increases slowly with $\mathrm{x}$ increases. By comparing and analyzing we can know that when $\mathrm{x}$ is constant the pulling force increases with the increase of $y$ value. And the y value has great effect on the pulling force when $\mathrm{x}<2$.5. This can be attributed to the influence of the $\alpha$ angle on the pulling force. $\sin \alpha$ is increased with the increase of the $\alpha$ angle when $0<\alpha<\pi / 2$. And $\sin \alpha=\sqrt{\frac{x^{2}+y^{2}}{x^{2}+y^{2}+z^{2}}}$, When $x$ small is, $y$ value accounts for a large proportion in the fraction, so $\mathrm{y}$ have a great influence. When the $\mathrm{x}$ value is more larger, because the maximum value of $\mathrm{y}$ is 0.9 and the maximum value of $\mathrm{x}$ is 4 , the effect of $\mathrm{y}$ value on the $\alpha$ angle is very small. The $\alpha$ angle has a direct influence on the size of the pulling force. The change of pulling force along with $\alpha$ angle is shown in Figure 7. Pulling force decreases rapidly with the decrease of the $\alpha$ angle, and reaches the minimum value near $55^{\circ}$, then increases. It is consistent with the trend shown in Figure 6.

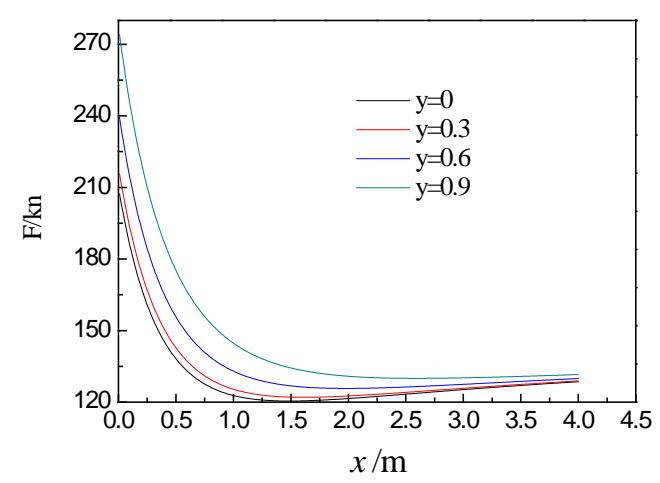

FIGURE 6, The change of $\mathrm{F}$ along with $x$

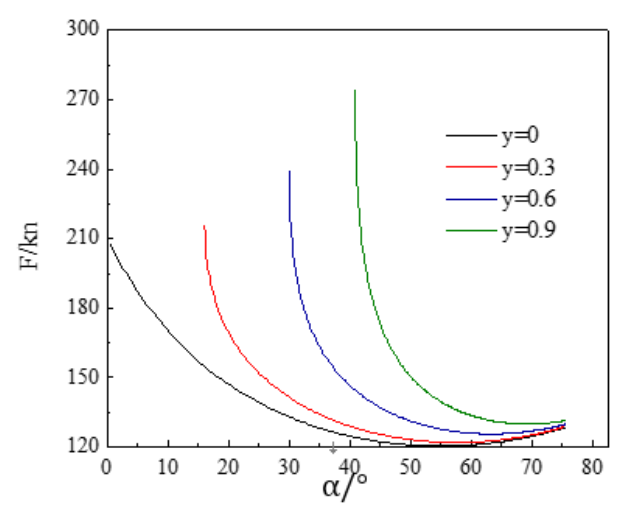

FIGURE 7, The change of $F$ along with $\alpha$

After analysis we can know that the pulling force increases with the increase of $y$, and decreases with the increase of $\mathrm{x}$ and then increases slowly. Optimization results are shown in Table 2:

TABLE 2, Optimization results

\begin{tabular}{cc||cc}
\hline \multicolumn{2}{c||}{$\begin{array}{c}\text { position of front } \\
\text { securing point }\end{array}$} & \multicolumn{2}{c}{$\begin{array}{c}\text { position of rear } \\
\text { securing point }\end{array}$} \\
\hline$x$ & $1.64 \mathrm{~m}$ & $x$ & $0.96 \mathrm{~m}$ \\
$y$ & $0 \mathrm{~m}$ & $y$ & $0 \mathrm{~m}$ \\
$\alpha$ & $55.1^{\circ}$ & $\alpha$ & $56.7^{\circ}$ \\
$\theta$ & $0^{\circ}$ & $\theta$ & $0^{\circ}$ \\
$F$ & 120.464 & $F$ & $120.464 \mathrm{kn}$ \\
\hline
\end{tabular}

Data in Table 2 shows that the y values are zero. This means that the equipment won't overturn and move in lateral, so $\theta=0^{\circ}$.

\section{CONCLUSION}

This paper analysis the pulling reinforcement of railway transportation in theoretical through the establishment of mechanical model and mathematical model. And this paper presents a method to calculate the best value by MATLAB. It enriches the theory of railway transportation loading and strengthening and lay the theoretical foundation for the design of chain reinforcement equipment. 
Through the simulation optimization calculation, the conclusions are summarized as follows.

(1)Because the friction of equipment and flat car floor is larger and the lateral inertia force is smaller, the lateral stability of the equipment is guaranteed.

(2)The optimal point of the equipment is determined by the parameters of itself. And the optimal point is in the middle part of the floor, rather than the position of rope lug on both sides of the floor. The location of rope lug and optimal securing point is quite different.

(3) In the process of railway transportation, the longitudinal inertia force is the biggest threat to the security of equipment transportation. Therefore, in the process of transportation and reinforcement, the longitudinal inertia force of cargos should be reduced as far as possible.

\section{REFERENCES}

[1] Wang Sen, Wang Xiao-an, Zhang Yan-Ping, The current development of the chain-type tiedown equipment for railway transportation of the US army and its enlightenments to our army [J], Traffic Engineering and Technlology for National Defence, 2014,(01):64-66.

[2] Zeng Yunqing, Wang Kang, Xin Xin, Standardized Blocking and Bracing Devices for Railway Transportation of U.S. Army's Wheeled and Tracked Equipments [J], Traffic Engineering and Technlology for National Defence, 2011(01):49-52.

[3] Ministry of Railways, Railway Freight Loading Reinforcement Rules [M]. Beijing: Chinese Railway Press, 2006.

[4] Dai Shi, Railway Freight Traffic Organization [M]. Beijing: Chinese Railway Press, 2007.

[5] Gai Yu-Xian, The Mechanical Cmputation about Reinforcing Goods with Iron Wires or Steel Wire Ropes [J]. Lanzhou: Journal of Lanzhou railway institute,1995:54-58.

[6] Jing Xianghe, Zhou Xianzhong, Xu Yanyong, Model and Algorithm for Pallet Loading Problem in Railway Transportation [J], Computer Engineering, 2006, 32(18):197-199.

[7] Wang Wujian, Safety and Reliability Analysis of Components of Railway Flat Wagon [J], Railway Locomotive \& Car, 2012, 32(6):21-24.

[8] Zhang Zhiqiang, Huang Cheng, Xu Kaiqi, Analysis on Reinforcement Strength Calculation in Railway Freight Loading Reinforcement Rules [J], Journal of Military Transportation University,2014,16(7):25-30. 